\title{
Ensino e Aprendizagem de Matemática Através da Resolução de Problemas Como Prática Sociointeracionista
}

\author{
Teaching and Learning Mathematics Through Problem Solving As \\ Sociointeractionist Practice
}

\author{
Luiz Carlos Leal Junior \\ Lourdes de la Rosa Onuchic ${ }^{* *}$
}

\begin{abstract}
Resumo
Neste artigo apresentamos uma experiência efetivamente prática e a abordagem do Ensino e da Aprendizagem de Matemática através da Resolução de Problemas, como prática sociointeracionista, desde suas constituições teórica e filosófica à sua prática educacional em um curso do Programa Nacional de Acesso ao Ensino Técnico e ao Emprego, dirigido pelo Instituto Federal de São Paulo - Campus Sertãozinho. Apresentamos um campo de estudo social, histórico e cultural como proposta da Resolução de Problemas, não apenas como uma metodologia de ensino-aprendizagem, mas sim como um campo de estudos que mantém vivo o movimento de ação/reflexão/ação por meio de conceitos e problemas da obra de Vygotsky. Lançamos mão dos elementos da autorregulação e metacognição pelo pensar-em-alta-voz na construção do conhecimento e na constituição da aprendizagem, além de alguns desdobramentos dessa prática no âmbito escolar.
\end{abstract}

Palavras-chave: Ensino-Aprendizagem. Resolução de Problemas. Prática Sociointeracionista. Pensar-em-AltaVoz. PRONATEC.

\begin{abstract}
This article presents a truly practical experience and the approach of Teaching and Learning Mathematics through Problem Solving, as a sociointeractionist practice, from its theoretical and philosophical constitutions to their educational practice in a course of the Programa Nacional de Acesso ao Ensino Técnico e ao Emprego headed by Instituto Federal de São Paulo - Campus Sertaozinho. We present a field of social, historic, and cultural studies as proposed by Problem Solving, not only as a teaching-learning methodology but rather as a field of study that keeps alive the move action /reflection/ action and through concepts and problems in Vygotsky's work. Lay hold of the self-regulatory and metacognition elements by thinking-out-loud in the construction of knowledge and creation of learning and some consequences of this practice in schools.
\end{abstract}

Keywords: Teaching-Learning. Problem Solving. Sociointeractionist Practice. Thinking-Out-Loud. PRONATEC.

\footnotetext{
* Doutorando em Educação Matemática pela Universidade Estadual Paulista (UNESP), de Rio Claro/SP. Mestre em Matemática pela Universidade de São Paulo (USP), São Carlos/SP. Membro do Grupo de Trabalho e Estudo em Resolução de Problemas (GTERP), UNESP, Rio Claro/SP. Professor do Instituto Federal de São Paulo (IFSP), Sertãozinho/SP. Endereço para correspondência: Rua Margarida, n. 156, ap. 03, Ribeirão Preto/SP, CEP: 14091-070. E-mail: jhcleal@gmail.com.

** Doutora em Matemática pela Universidade de São Paulo (USP), São Carlos/SP. Coordenadora do Grupo de Trabalho e Estudo em Resolução de Problemas (GTERP), UNESP, Rio Claro/SP. Professora e pesquisadora voluntária do Programa de Pós-Graduação em Educação Matemática da Universidade Estadual Paulista (UNESP), Rio Claro/SP. Endereço para correspondência: Rua Machado de Assis, n. 302, Santa Bárbara d'Oeste/SP, CEP: 13451-000. E-mail: Ironuchic@gmail.com.
} 


\section{Introdução}

Este artigo se propõe a tratar da abordagem de atividades de Educação Matemática, utilizando a metodologia de ensino-aprendizagem de Matemática através da Resolução de Problemas, desenvolvidas no curso de Traçador de Caldeiraria do Programa Nacional de Acesso ao Ensino Técnico e Emprego - PRONATEC - do Instituto Federal de São Paulo IFSP, campus Sertãozinho, durante o primeiro semestre do ano de 2014. Mas não simplesmente como uma metodologia, e sim como uma nova perspectiva da filosofia da Educação Matemática, ao mantermos vivos os movimentos de Ação/Reflexão/Ação que, segundo Bicudo (2010, p. 23), “tem como foco de estudo a própria análise reflexiva e crítica da produção", elemento este que abordaremos e utilizaremos lançando mão de estudos multidisciplinares para fundamentar a perspectiva que desejamos apresentar.

O curso Traçador de Caldeiraria foi escolhido por apresentar em seu plano (elaborado pelo IFSP) muitos conteúdos de Matemática e, consequentemente, muitos conceitos matemáticos; além disso, por possuir uma carga horária total de 50 horas e uma turma de 20 estudantes. Essa carga horária mostrou-se contraproducente, uma vez que o tempo a ela destinada foi insuficiente para o trabalho dos conteúdos requeridos no referido plano que tem preocupação com a aprendizagem. Mas faremos nossas considerações em cima das propostas e dos objetivos do plano de curso ${ }^{1}$, que nos foi dado como diretriz ao mesmo.

Este curso tem como requisito mínimo para ingresso o Ensino Fundamental II completo $^{2}$, o que, de fato, nos proporcionou um cenário muito interessante para investigação: a sala era composta por sujeitos de diversas idades, variando de 17 a 51 anos; estudantes que cursavam o $1^{\circ}$ ano do Ensino Médio a estudantes que já não frequentavam o ambiente escolar há mais de 40 anos; pessoas que trabalhavam numa jornada de 8 a 10 horas diárias e que utilizavam o período noturno para a realização do curso; e estudantes oriundos da Fundação Casa $^{3}$.

Numa conversa com a turma, pudemos perceber que suas intenções em fazer esse curso se davam visando uma oportunidade de emprego, como requisito de reabilitação, ou apenas para receberem a ajuda de custo, como um prolabore pago pelo governo federal, para

\footnotetext{
${ }^{1}$ Mais detalhes sobre este PPC em Brasil (2013).

${ }^{2}$ Período compreendido atualmente entre o $6^{\circ}$ e o $9^{\circ}$ anos da educação básica.

${ }^{3}$ A Fundação Centro de Atendimento Socioeducativo ao Adolescente (FUNDAÇÃo CASA/SP) é uma autarquia fundacional (pessoa jurídica de direito público) criada pelo Governo do Estado de São Paulo (Brasil). Sua função é a de executar as medidas socioeducativas aplicadas pelo Poder Judiciário aos adolescentes autores de atos infracionais com idade de 12 a 21 anos incompleta, conforme determina o Estatuto da Criança e do Adolescente (ECA). Fonte: wikipedia em março de 2015.
} 
custear seus gastos. Enfim, este foi um cenário muito diversificado e complementar a uma proposta de ensino de Matemática que pudesse mostrá-la aos alunos, de forma útil e necessária às suas formação e realidade.

A escolha da metodologia de ensino de Matemática deu-se através de estudos do professor da turma, baseados em trabalhos na linha de pesquisa - Resolução de Problemas e Ensino e Aprendizagem de Matemática -, principalmente esteados nas propostas do Grupo de Trabalho e Estudo em Resolução de Problemas - GTERP, da UNESP/Rio Claro, que vem a ser o núcleo gerador de atividades de aperfeiçoamento, investigações e produção científica nessa linha.

Tal trabalho tem como mote a discussão de práticas que venham a contribuir significativamente para a formação de estudantes e professores; promover o movimento da ação reflexiva e suas implicações sobre novas ações; e colaborar, em outros cenários, com abordagens pedagógicas de conteúdos de Matemática, em turmas com dificuldades na aprendizagem, em que o ensino esteja pautado por uma estruturação estratificante e tradicional diante da singularidade dos sujeitos que compõem o processo de ensinoaprendizagem $^{4}$.

\subsection{Uma Apresentação do Curso do PRONATEC}

De início, para o ensino de Matemática nos cursos do PRONATEC trabalhados pelo professor, foi elaborada uma apostila de Matemática Básica ${ }^{5}$, como material para direcionar o ensino e, supostamente, promover a aprendizagem, já que era uma exigência da instituiçãosede. Esse modo de trabalho já havia sido aplicado em outros cursos de mesma natureza, por meio da abordagem tradicional e enciclopédica dos conteúdos. Ao final desses cursos, os estudantes manifestaram inquietações e dificuldades que nos levaram a compreender que, para eles, os modos pelos quais o curso propunha o ensino-aprendizagem não se adequava às expectativas de uma possível formação profissional. Essa percepção dos alunos deu suporte

\footnotetext{
${ }^{4}$ Neste trabalho utilizamos o entendimento de Paulo Freire para justificar a utilização do termo ensinoaprendizagem. Para ele não existe ensino sem aprendizagem. A educação, como ensinamentos, é um processo dialógico, um intercâmbio constante. Nessa relação, educador e educando trocam de papéis o tempo inteiro: o educando aprende ao passo que ensina seu educador e o educador ensina e aprende com seu estudante. Para este pensador, dentro do processo educacional, estudantes e professores devem assumir seus papéis conscientemente - não são apenas sujeitos do "ensinar" e do "aprender" e, sim sujeitos com histórias e trajetórias singulares. (FREIRE, 1996).

${ }^{5}$ Essa Apostila de Matemática Básica pode ser acessada no repositório do IFSP ou no site <http://www.cefetsp.br/edu/sertaozinho/professores/Luiz_Carlos_Leal_Junior/UntitledFrameset-2.html >. Acesso em 19 de junho de 2015.
} 
para a compreensão dos resultados que os mesmos obtiveram ao final do curso, que, segundo o professor, se mostraram aquém do desejado.

Algumas questões como: "Para que eu precisarei usar isso no meu serviço?" ou "Se não consigo entender, quem dirá resolver isso ai!!” foram colocadas por alguns estudantes naquela perspectiva de ensino. Isso motivou o professor a buscar um movimento, um caminho que fosse pertinente e que pudesse, senão responder aos questionamentos, possibilitar uma reflexão sempre crítica, um pensamento diferenciado para os estudantes a respeito de suas interrogações. Foi quando se recorreu à Resolução de Problemas como abordagem didática e processo de construção de conhecimento, não simplesmente como estratégia de ensino.

Em março de 2014, deu-se início ao curso Traçador de Caldeiraria, onde a primeira aula foi ministrada buscando-se conhecer o perfil dos estudantes, seus anseios e perspectivas a ele relativas, além do quê e do porquê esse curso lhes poderia ser útil. Foi quando o professor lhes apresentou uma dinâmica de ensino-aprendizagem, em que não atuariam como meros espectadores, eles seriam também autores e ativos participantes de todas as atividades. No primeiro encontro, algo se destacou. Alguns estudantes que, supostamente, deveriam estar alfabetizados e dominar a escrita, por terem o nível exigido de escolaridade para o curso, sequer conseguiam expressar suas ideias, talvez por terem permanecido afastados do ambiente de formação escolar, o que lhes causou um deficit na formalização e na expressão do pensamento, mas que, por outro lado, lhes possibilitou, a priori, um acúmulo de experiências e conhecimentos.

Diante desse quadro, após o trabalho mediado pela metodologia de ensinoaprendizagem de Matemática através da Resolução de Problemas, os resultados foram promissores e gratificantes. Não resultados em termos quantitativos, mas qualitativos. Acreditamos que esta iniciativa pôde proporcionar reflexões e práticas significativas e benéficas para trabalhos que permeiam o ensino-aprendizagem de Matemática em programas que sejam compostos por turmas diversificadas e múltiplas, no sentido de suas dificuldades e carências.

\section{Ensino-Aprendizagem: uma fundamentação teórica para Resolução de Problemas.}

Nos Standards $2000^{6}$ pode-se encontrar a metodologia que se buscou para ensinar Matemática através da Resolução de Problemas, que aponta o problema como objeto que

\footnotetext{
${ }^{6}$ Standards 2000 é a denominação não-oficial dos Principles and Standards of School Mathematics, uma publicação do National Council of Teachers of Mathematics - NCTM-dos Estados Unidos da América.
} 
inicia e fomenta a construção e a formação de um novo conceito matemático, por meio da sua produção ativa e da constituição da Matemática através da sua prática. Nesta concepção os estudantes passam a ter participação efetiva na constituição de sua aprendizagem, ou seja, são coautores da mesma e os professores são os incentivadores e mediadores desse processo através das atividades de ensino.

Para justificar a utilização da Resolução de Problemas, não apenas como uma metodologia para se ensinar Matemática, mas como um campo de estudos filosóficos que promove a aprendizagem, apresentaremos as possibilidades de ações, reflexões, operações e aplicações que ela traz ao processo de ensino-aprendizagem no corpo deste trabalho, onde muitas vezes recorremos à filosofia da Educação Matemática, à psicologia, à epistemologia, à ontologia, etc.

Para nós, a Resolução de Problemas tem natureza sociointeracionista, já que o foco de sua atividade reside na base histórico-dialética, conforme diz Duarte (1996), e não apenas interacionista e construtivista pela obra de Vygotsky, como muito se prega em trabalhos acadêmicos.

Os problemas propostos não terão, aqui, a prática de atividades de cunho repetitivo e recognitivo, embora reconheçamos a importância da recognição para a ativação e a potencialização dos conhecimentos, trazidos a priori pelos estudantes, para a constituição de sua aprendizagem. Por sua vez, o sentido do termo repetição é aquele que se apresenta como reforço, repetir algo já feito, algo que não apenas cria um novo conceito, mas sim potencializa sua fixação/internalização.

Em outro olhar, Vygotsky se apropria da palavra imitação, concedendo-lhe o sentido pelo qual o ensino pode ser trabalhado, pois “[...] para se imitar é preciso ter alguma possibilidade de passar do que sei ao que não sei. [...] sendo a imitação a forma principal pela qual se leva a cabo a influência da instrução sobre o desenvolvimento" (VYGOTSKI, 1993, p. 241, tradução nossa).

$\mathrm{Na}$ esteira dessas considerações, buscamos atuar nos desdobramentos e bifurcações das práticas de criação e invenção ${ }^{7}$, onde a criação se observa na resolução de problemas ${ }^{8}$ e a invenção se reflete na proposição de problemas. A criatividade atua como uma potência inerente aos agenciamentos e aos acontecimentos no pensamento dos estudantes, que ao se depararem com os problemas, buscarão meios para resolvê-los. A invenção, na perspectiva da

\footnotetext{
${ }^{7}$ Para uma leitura mais profunda sobre representação, recognição, criatividade e invenção recomendamos a leitura de Cassiano; Andrade (2010) e Rocha; Pinheiro (2011).

${ }^{8}$ resolução de problemas (letras minúsculas) refere-se ao ato de resolver problemas, enquanto Resolução de Problemas (letras iniciais maiúsculas), à teorização da Resolução de Problemas.
} 
Resolução de Problemas, tem seu início na concepção do problema, onde o professor o inventa com base no construto sócio-histórico-cultural para estimular a aprendizagem dos estudantes e subverter o modelo representacionalista e tradicional de ensino.

Em Vygotsky (2009), o autor apresenta o conceito de atividade criadora, que trata da criação de algo novo, algo inaugural no modo de pensar - produção de algo novo no pensamento, como este conceito se dá e por que meios ele atua. Em uma atividade criadora, a representação se configura no estabelecimento e na preservação da experiência que o sujeito produziu ou vivenciou e que faz com que ele se aproprie dos elementos do mundo pela sua aprendizagem.

Consoante o pensamento de Cassiano \& Andrade (2010, p. 57), citamos:

\begin{abstract}
Essa reprodução é fruto da capacidade de conservação cerebral que funciona em conjunto com outra capacidade cerebral: a atividade criadora. E, quanto à conservação, é voltada para o passado e para o presente, reproduzindo nossa experiência anterior, a imaginação [...] seria a atividade criadora voltada para 0 futuro, para a invenção, capaz de transformar a natureza e o homem.
\end{abstract}

Para Vygotsky, todo sujeito tem a capacidade de criar e as atividades criadoras advém de suas experiências a priori. Ele entende, assim como nós, a criatividade como processualidade e a interpreta como descoberta de novas soluções, ao passo que, para ele, a invenção está idiossincraticamente relacionada.

\title{
2.1 Resolução de Problemas e seus desdobramentos sociointeracionistas
}

O trabalho em grupos, como uma proposta de estudos, tem o caráter interacionista, tratando da interação entre subjetividades que, para Vygotsky, é sempre "[...]uma interação historicamente situada, mediatizada por produtos sociais, desde os objetos até os conhecimentos historicamente produzidos, acumulados e transmitidos." (DUARTE, 1996, p. 30). Contamos com a perspectiva de que cabe, ao professor de Matemática, ensinar, colocar os estudantes efetivamente em contato com conceitos formativos da Matemática e participar ativamente disso, assumindo o papel de coautores da aprendizagem.

Vygotsky diz que o bom ensino é aquele pautado pela transmissão do que o estudante não conseguirá descobrir sozinho e pela conceituação de imitação, que vem a ser o cerne dos conceitos vygotskyanos de Zona de Desenvolvimento Proximal (ZDP), Nível de Desenvolvimento Real (NDR) e Nível de Desenvolvimento Potencial (NDP).

A Zona de Desenvolvimento Proximal, em termos da Resolução de Problemas, é o locus da cognição, onde as atividades encontram atuação e operação na promoção da 
aprendizagem matemática, sendo que essa aprendizagem advém das relações do ensino, do desenvolvimento cognitivo na idade escolar e da difusão do conhecimento socialmente existente ${ }^{9}$.

Assim, a ZDP, comumente definida pela diferença entre o NDP e o NDR, engloba tudo aquilo que o sujeito não consegue realizar sozinho, mas que terá êxito ao obter o auxílio de alguém que o saiba fazer. Portanto, quando num curso propõem-se problemas aos estudantes, deve-se refletir nos propósitos atribuídos aos mesmos e nos objetivos dos estudantes, dado que se busca atuar em suas ZDP's que têm limites para imitação.

Não estamos falando de limitar a aprendizagem de um sujeito ao seu NDR, mas, como propõe Vygotsky, situar o ensino, que ele chama de bom, àquele potencializado e desenvolvido na ZDP.

Quando observamos o curso do desenvolvimento da criança durante a idade escolar e no curso de sua instrução, vemos que, na realidade, qualquer matéria exige da criança mais do que esta pode dar nesse momento, isto é, que esta realiza na escola uma atividade que a obriga a superar-se. [...]. Esta situação real se produz sempre que a instrução é fecunda. [...] Ensinar a uma criança aquilo que é incapaz de aprender é tão inútil como ensinar-lhe a fazer o que é capaz de realizar por si mesma. (VYGOTSKI, 1993, p. 244-245, tradução nossa).

Enfatizamos o ensino através da Resolução de Problemas para balizar nossa atuação baseados na mediação entre o desenvolvimento cognitivo e a aprendizagem escolar. Dessa forma a Resolução de Problemas opera transversalmente através dos conceitos vygotskyanos da ZDP, do NDR e do NDP como um meio para aprendizagem em uma relação de imanência, onde são considerados todos os elementos que o compõe para potencializar a construção do conhecimento.

Afirmamos, então, que este processo de trabalho educacional, no âmbito da Matemática, contribui significativamente para o desenvolvimento cognitivo e histórico-social, tendo contribuições tanto interacionistas, quanto construtivistas, mas não sendo por elas definido. Esse trabalho não é apenas visto como um meio para o ensino-aprendizagem, e sim como um produto social, estabelecido de atividades e práticas.

\subsection{Problemas e conceitos}

Em Pensamento e Linguagem, Vygotsky (2008) elabora um discurso sobre os modos de organização das funções psicológicas superiores ${ }^{10}$, quando diz que os conceitos se dão nas

\footnotetext{
${ }^{9}$ Para um leitor mais interessado indicamos a leitura de Duarte (1996).

${ }^{10}$ São funções psicológicas superiores: a capacidade de planejamento, a memória voluntária, a imaginação, a, abstração, a generalização, etc. Segundo Vygotsky, as funções psicológicas superiores não são inatas, “elas se
} 
experiências imediatas, no cotidiano. O pensador estabelece e discorre sobre as relações entre os conceitos científicos e os conceitos espontâneos. Não estenderemos as discussões acerca das definições de conceito que Vygotsky produziu, mas indicamos, para um leitor mais interessado no tema, a leitura da obra citada, que será objeto de estudos futuros.

Os conceitos espontâneos decorrem de confrontos de situações concretas no âmbito social que

São categorias ontológicas, intuitivas e próprias de cada indivíduo, desenvolvidas sem a necessidade de escolarização formal. Por isso, são conceitos assistemáticos, originados em situações contextualizadas, cujas relações são orientadas por semelhanças concretas e por generalizações isoladas. (DAMÁZIO, 2000, p.54).

Os conceitos científicos, por sua vez, são traduzidos pelas relações objetivas das teorias formais, sendo formulados historicamente pela cultura e não pelo sujeito. Para se apropriar desses conceitos há a necessidade de ações mediadas, como o ensino. Damázio (2000) diz que eles "têm como características fundamentais um alto nível de sistematização, de hierarquização e de logicidade, expressas em princípios, leis e teorias.” (Ibidem, p.54). Vygotsky revela o desenvolvimento dos conceitos científicos no interior do processo de ensino-aprendizagem. Esses conceitos são apreendidos pelos sujeitos num processo consciente e intencional.

A relação entre esses dois tipos de conceito se dá através de uma relação dialética. Entretanto, destacamos que os conceitos espontâneos e os conceitos científicos, a princípio, permanecem afastados, dado que seu desenvolvimento acontece em direções contrárias, mas acabam se encontrando em algum momento (VYGOTSKY, 1993).

Não obstante, Vygotsky (1991) destaca que é necessário ao conceito espontâneo alcançar certo nível de sistematização para que o conceito científico correspondente seja estabelecido. Logo, mediante a nossa teorização pela Resolução de Problemas, em princípio, os conceitos espontâneos, bem como os conhecimentos científicos já apreendidos pelos sujeitos e suas experiências já são conhecidos a priori. Todavia, os conceitos que serão construídos pelos problemas na Resolução de Problemas, dentro do processo de ensinoaprendizagem, são conceitos matemáticos que, por sua vez, são conhecimentos científicos ainda não apreendidos.

Assim sendo, temos que destacar, nesta proposta, o objeto que perpassará esse processo, a saber, o problema. Para nós o problema é o condutor, um meio de fazer as conexões, utilizado pelo professor para possibilitar, aos estudantes, o encontro formativo com

originam nas relações entre indivíduos humanos e se desenvolvem ao longo do processo de internalização de formas culturais de comportamento". (REGO, 2003, p.39). 
os conceitos matemáticos. Mas, quando falamos de problemas e conceitos, queremos destacar que os problemas conduzem a novos conceitos e, utilizando os conceitos adquiridos a priori ${ }^{11}$ podem ser resolvidos. Um problema não se restringe à produção e à formalização de um único conceito, mas de novos conceitos.

Outrossim é necessário pensar-se na composição dos problemas, que trazem conceitos e resultados cognitivos a respeito das atividades que o compõe. A noção de problema que utilizaremos está de acordo com Onuchic e Alevatto (2011, p. 81), onde problema é "tudo aquilo que não se sabe, mas que se está interessado em fazer”. Dessa forma cabe, ao professor, motivar os estudantes a participarem das resoluções dos problemas e de entenderem os conceitos neles contidos e os que se quer alcançar. Caso contrário, não será possível a promoção da aprendizagem, por se partir do pressuposto de que os estudantes não o sabem fazer, mas precisam do fator motivacional para se interessarem em fazê-lo.

Todavia, o docente necessita trabalhar na formulação da proposta do problema, levando em consideração o potencial do estudante e seus conhecimentos adquiridos a priori ${ }^{12}$, o que lhe permitirá construir ferramentas para resolver problemas e constituir a própria aprendizagem. Dessa forma cabe, tanto ao professor quanto ao estudante, uma postura ativa e participativa que ultrapasse a resolução do problema por si só. A construção do conhecimento deve ser o foco da Resolução de Problemas que, por ter início com o docente, deve ser concebida de tal forma a possibilitar ao estudante a responsabilidade e a consciência de sua atitude diante da formação pretendida.

Para evitar problemas de cunho metodológico, o docente necessita de muitos estudos, preparações e conhecimentos sobre a classe/turma onde atua, para não propor problemas fora de contexto e muito além das condições de resolução dos estudantes. Onuchic e Allevato (2004, 2011) propõem seis princípios sobre a Resolução de Problemas que devem ser ponderados antes de qualquer atividade relacionada:

- Resolução de Problemas coloca o foco da atenção dos estudantes sobre ideias
matemáticas e sobre o dar-lhes sentido. • Resolução de Problemas desenvolve um
poder matemático nos estudantes, ou seja, uma capacidade de pensar
matematicamente, utilizar diferentes e convenientes estratégias em diferentes
problemas, permitindo aumentar a compreensão de conteúdos e conceitos
matemáticos. • Resolução de Problemas desenvolve a crença de que os estudantes
são capazes de fazer Matemática e de que a Matemática faz sentido; a confiança e a
autoestima dos estudantes aumentam. • Resolução de Problemas fornece dados de
avaliação contínua, que podem ser usados para a tomada de decisões instrucionais e
para ajudar os estudantes a obter sucesso com a Matemática. • Professores que
ensinam dessa maneira se empolgam e não querem voltar a ensinar na forma dita
tradicional. Sentem-se gratificados com a constatação de que os estudantes

${ }^{11}$ Doravante apenas conceitos a priori.

${ }^{12}$ Doravante apenas conhecimento a priori. 
desenvolvem a compreensão por seus próprios raciocínios. • A formalização dos conceitos e teorias matemáticas, feita pelo professor, passa a dar mais sentido para os estudantes. (Idem, 2004, p. 223-4).

Não há métodos específicos e rígidos para o trabalho na perspectiva da Resolução de Problemas, até porque cada estudante é um ser singular, que compõe grupos singulares na multiplicidade da sala de aula, e cabe, ao docente, o reconhecimento desses fatores na hora de se propor problemas visando ao aprendizado. A partir dessa afirmação, Onuchic et al. (2014) apresentaram um roteiro para auxiliar os professores na elaboração do planejamento de suas aulas, e que foi vivido neste trabalho com a turma do PRONATEC, que abordaremos adiante. Tal roteiro consiste, em suma, de dez passos. Não se pretende com eles restringir a atividade em classe, mas fornecer subsídios para a atuação de professor e de estudantes nesta processualidade. São eles:

(1) Proposição do problema, (2) leitura individual, (3) leitura em conjunto, (4) resolução do problema, (5) observar e incentivar, (6) registro das resoluções na lousa, (7) plenária, (8) busca do consenso, (9) formalização do conteúdo, (10) proposição e resolução de novos problemas. (Idem, Ibidem, p. 45).

Também é certo que para o trabalho com essa metodologia, seja necessário que os sujeitos envolvidos estejam desterritorializados e livres das amarras de certos planejamentos de conteúdos e currículos sequencialmente instituídos para um determinado período letivo, haja vista que os problemas podem potencializar o estudo e promover uma busca por outro conceito diferente, mas indispensável à situação.

\subsection{Metacognição e autorregulação na Resolução de Problemas}

González (1998) aventou um modelo para a metacognição e a Resolução de Problemas, ao tratar dos problemas contextualizados como Tarefa Intelectualmente Exigente - TIE ${ }^{13}$. Não acreditamos que o ensino-aprendizagem possa acontecer de maneira linear dentro desse modelo, ou obedeça alguma ordem, mas sim que ele perpasse os elementos indicados pelo autor e que eles estejam diretamente inter-relacionados de maneira idiossincrática. Os fins: caracterizam-se pelos objetivos finais do problema proposto; As ações: se consistem dos meios pelo quais o estudante se utiliza para resolver os problemas; Os conhecimentos: trata-se de um elemento cognitivo, que se baseia nos conhecimentos a priori, nas crenças que os estudantes têm sobre o mundo e si mesmos; As experiências: são as concepções que os estudantes adquirem em situações semelhantes e a partir das reflexões dos resultados

\footnotetext{
${ }^{13}$ Conforme Flores-Mendoza \& Colom (2008) um problema matemático é uma TIE, onde se requer estratégias cognitivas para aprender e conseguir êxito no seu processo de resolução.
} 
experienciados.

Aliada a esses elementos está a autorregulação que, segundo Frison (2006), é um processo que auxilia os sujeitos no estabelecimento dos objetivos e no desenvolvimento de estratégias de aprendizagem diante dos problemas propostos. Estratégias essas, mais eficazes e potencializadoras, tanto para estudarem e criarem suas respostas, quanto para obterem uma postura diferenciada e ativa na construção do conhecimento. A recognição, o pensamento, os conceitos e conhecimentos a priori e a visualização de resultados compõem o movimento de autorregulação, que permite aos sujeitos o avanço em seus estudos.

Por sua vez, a metacognição vem a ser "qualquer conhecimento ou atividade cognitiva que toma, como seu objeto, qualquer aspecto de qualquer iniciativa cognitiva" (FLAVELL; MILLER; MILLER, 1999, p. 125). Esse conceito atravessa nossa proposta de trabalho e entendemos que ela se comporta como uma atividade cognitiva onde o estudante narra como aprendeu - o pensar-em-alta-voz ${ }^{14}$, ou como aprendeu a aprender, que diz respeito ao/a movimento/atitude que se configura por meio da autorregulação e da metacognição no âmbito de uma prática sociointeracionista voltada para o ensino-aprendizagem.

Sobre esse raciocínio, Zuffi e Onuchic (2007) dizem:

\begin{abstract}
Quando se aplica a metacognição no processo de resolver problemas, faz-se referência ao conhecimento consciente que o resolvedor tem acerca da especificidade desse processo e da autorregulação deliberada que tem no mesmo, levando em conta os fatores que condicionam a situação-problema, planejando suas ações e executando e avaliando os resultados. (Ibidem, p. 86)
\end{abstract}

Expostas essas considerações sobre a Resolução de Problemas, buscamos sempre nos afastar do ensino distante da realidade dos estudantes, sem dar sentido à sua aprendizagem, evitando a simples representação de conceitos e o decorar de fórmulas e conteúdos. Esse fato causa profundo prejuízo ao ensino-aprendizagem, bem como uma má explicação ou motivação sobre o uso e a aplicação de conceitos sob a égide da argumentação de que os estudantes aprenderão o conceito num momento e sua função e aplicação serão aprendidas posteriormente, caso este que aponta para um obstáculo didático ao ensino-aprendizagem.

Assim, as questões que nos surgem decorrentes desse pensamento são: por que ensinar um conteúdo sem a base necessária à sua formalização e seu entendimento? Como aprendê-lo?

Não fornecemos respostas diretas a essas questões, mas apresentamos o motivo de

\footnotetext{
${ }^{14}$ Esse termo se diferencia do pensar-em-voz-alta, que se refere a uma atividade de leitura, recognição, simples percepção, atividade de introspecção ou expor o que se pensa de maneira audível, como muito se percebe em materiais de cunho psicológico que tratam do assunto. Para um leitor mais interessado no assunto aconselhamos a leitura de Reis; Löber; Bolzan (2013).
} 
nossa escolha pela Resolução de Problemas, como proposta de um ensino diferenciado que atenda às necessidades das salas de aula, heterogêneas e múltiplas em suas constituições, e que nos faz pensar e refletir em nossas ações e práticas para evitar esses questionamentos e, por fim, esse status quo.

\section{0 cenário das salas de aula}

A turma escolhida para se trabalhar o ensino de Matemática através da Resolução de Problemas faz parte do programa PRONATEC, desenvolvido na cidade de Sertãozinho ${ }^{15}$ / SP e teve a duração de 18 semanas. Durante esse período pudemos constatar fatos importantes e que essa proposta mostrou-se interessante à situação criada, uma vez que o conteúdo programático foi bastante extenso e variado para o prazo estabelecido.

É importante enfatizar que nenhum dos estudantes dessa turma havia tido algum contato com uma forma de ensino diferente da tradicional. A metodologia de Resolução de Problemas foi novidade tanto para estudantes quanto para o professor. Nossa pesquisa baseouse em relatos do professor e dos estudantes, bem como em análise das narrativas produzidas pelos mesmos durante as resoluções de problemas e na atividade do pensar-em-alta-voz sobre a ação. Tais materiais encontram-se de posse do IFSP - Campus Sertãozinho, que administrou o programa.

\subsection{O problema, o envolvimento e as reflexões}

Informamos que, durante todo o curso, foram propostos onze problemas cunhados, de forma que os estudantes pudessem atuar ativamente na constituição de sua aprendizagem sobre diferentes conteúdos, assim organizados pelo professor: $1^{\circ}$ - Regras de três; $2^{\circ}$ - Unidades de medidas e transformações de unidades; $3^{\circ}$ - Polígonos convexos; $4^{\circ}$ - Circunferências e círculos; e, por fim, $5^{\circ}$ - Cálculos de áreas e volumes, onde para os $1^{\circ}$ e $3^{\circ}$, os estudantes já possuíam, supostamente, os conceitos de razão e proporção e ângulos e triângulos, respectivamente.

Aqui, daremos destaque para o primeiro assunto, pelo fato de que, para essa atividade, os estudantes suscitaram discussões e levantaram situações muito interessantes, até pelo

\footnotetext{
${ }^{15}$ Cidade conhecida pelo seu potencial de produção sucroalcooleira e metalomecânico. Um cenário favorável a estudos da área de serviços e tecnologia. Para uma leitura sobre esta cidade do ponto de vista estatístico e matemático leia Maciel; Leal Jr; Ribeiro (2011).
} 
motivo de ter sido o primeiro problema, o 'divisor de águas', nos mostrando a concepção de um ensino que prima pelo agenciamento dos estudantes com os conceitos matemáticos em busca de apreendê-los e operá-los em diversas situações de suas vidas.

A primeira aula de Matemática, ou seja, o primeiro encontro que ocorreu uma semana após o início do curso, pela disposição das disciplinas, o professor a utilizou para apresentar a proposta do curso, os conteúdos programáticos e conhecer os estudantes. Essa turma foi composta, documentalmente, por 20 estudantes matriculados, mas apenas 12 estavam frequentando efetivamente desde o início do curso. Foi proposta então a formação de dois grupos, de maneira aleatória e pelas escolhas dos próprios estudantes, cada um composto por seis estudantes. Na aula seguinte, intentando oferecer aos estudantes um problema sobre regras de três, que pudesse ser interessante aos contextos em que esses estudantes estivessem inseridos ou dispostos a capacitarem-se, propôs-se o seguinte problema:

Uma indústria, com 12 funcionários da rede de produção, constrói 156 unidades de uma determinada caldeira de pequeno porte em 13 dias. Supondo que a produção seja constante a cada dia, quantas dessas caldeiras são produzidas numa semana? Mas, devido a uma crise, essa indústria precisará demitir 5 funcionários. Quantos dias ela necessitará para conseguir manter a produção outrora semanal? (Material do professor, 16/03/2014).

Tão logo o problema foi entregue a cada estudante, o professor procedeu como no roteiro de Onuchic et al. (2014), sem nenhum problema na aplicação dos três primeiros passos: a preparação e as leituras (individual, coletiva e com o auxílio do professor). Então partiram para a resolução do problema.

Os dois grupos estavam confiantes porque em menos de 15 minutos já haviam resolvido a primeira parte do problema, ora escrito, ora mentalmente. Não obstante, todos seguiram o mesmo raciocínio de resolvê-lo por regra de três simples, inclusive estabelecendo a relação entre as informações e as grandezas, que porventura eram diretamente proporcionais, mas não a explicitaram nesses termos, o que levou o professor a perceber que não conheciam os conceitos de proporcionalidade, que viriam, então, a ser abordados no momento da formalização, sem perda de generalidade.

Porém, consideravam: “- Se uma semana tem 7 dias, vai diminuir de 13 pra 7; então o número de caldeiras também vai diminuir de 156 pra um número 'mais pequeno'”. Outro estudante do grupo: "Mas uma semana de trabalho não tem 7 dias, então não é pra usar 7 , temos que perguntar pro professor se 'é' 7, ou se 'é' 5, ou se são 6 dias [...]", ao que uma aluna responde: “- Se fosse pra pensar diferente de 7 ele teria dito, usou uma semana, e só! No problema, não falou uma semana de trabalho, ou coisa do tipo, até por que uma indústria não pára nos finais de semana, quem 'param' são alguns funcionários. [...] e se quer saber, é 
7! E pronto!". E a discussão continuou. Até que em algum momento uma senhora se manifestou: “- Professor, você não vai fazer nada não? Só vai ficar olhando? Eu não estou conseguindo entender! 'Vem' aqui! Eu consegui fazer a primeira parte sozinha, agora não sei começar a segunda!" (Material do professor, 16/03/2014).

Nos diálogos que seguem, não explicitaremos os nomes dos estudantes para preservar suas identidades, os indicaremos por nomes fictícios.

Pela segunda parte do problema, transcrevemos o diálogo do G1:

Daiane: - Agora que já sabemos que numa semana são produzidas 84 unidades temos que substituir.

Francisco: - Mas substituir 'aonde'? No problema anterior ele queria saber a quantidade de caldeiras, agora são dias [...] são coisas diferentes.

Professor: - Que coisas são essas? Como podemos caracterizá-las?

Aline: - Acho que são variáveis, ou incógnitas; não sei!

Roberto: - Eu lembro que incógnita é o que temos que descobrir, o que o problema está pedindo [...] e pensando assim, variável deve ser os dias, números de caldeira e o número de funcionários. [...] é isso professor?

Professor: - Por que você está chamando esses elementos de variáveis?

Roberto: - Por que elas variam de uma situação para outra!

Pedro: - Acho que não importa o nome que a gente dá pra essas coisas, mas o que a gente tem que fazer com elas.

Daiane: - Só sei que o número de dias vai ter que aumentar, por que vai diminuir o número de funcionários. (Material do professor, 16/03/2014).

E após esse diálogo, voltaram-se à leitura do problema. Enquanto isso, o G2 tentava esboçar alguma escrita em linguagem matemática.

Helena: - E se a gente fizesse como na regra de três que a gente fez? Colocar numa coluna os funcionários, na outra coluna os dias e na última o número de caldeiras? Será que vai ficar legal?

Israel: - Mas aonde vai o $x$ ?

Roseli: - Que x? Não estamos falando disso ainda.

Professor: - $O$ que vem a ser o x para vocês?

Israel: - O x é o que nós queremos descobrir, ou seja, a quantidade de dias do novo problema.

Heloiza: - Professor olha o que a gente montou e me diz se 'tá' certo?

[Nesse momento ela pega sua folha do fichário e mostra o que o grupo montou esquematicamente, em desacordo com a Roseli que não estava convencida do raciocínio: Lá havia uma tabela $3 X 3$, como a que segue]

\begin{tabular}{|c|c|c|}
\hline Funcionários & Caldeiras & Dias \\
\hline 12 & 156 & 13 \\
\hline 7 & 84 & $x$ \\
\hline
\end{tabular}

Professor: - Pois bem! O que vocês farão para encontrar o valor de $x$ ?

Heloiza: - multiplicaremos a primeira linha e faremos igual com a segunda linha.

Professor: - Mas qual o significado dessa ação? Por que fazer isso?

Roseli: - Ah! Professor, você não está ajudando nada, só complica! (Material do professor, $16 / 03 / 2014)$.

Muitos estudantes não estavam pensando na questão conceitual e no que aprender com o problema. Buscavam apenas, de um modo tradicional, através da repetição e da recognição, 
o uso ou a aplicabilidade de alguma fórmula para encontrar a solução. Ao que o professor lhes pediu a mudança de postura, para refletirem sobre o que estavam produzindo através daquele problema, uma vez que deveriam se interessar mais pelos meios de resolução, do que pela solução como um fim em si mesma. Orientou-os a apelarem à metacognição e autorregulação, atendendo ao pedido de utilizarem o movimento do pensar-em-alta-voz.

Num determinado momento, o G1 chamou o professor dizendo ter terminado o problema. E segue o diálogo:

Daiane: - Professor acabamos! Acabamos antes deles!

Professor: - Mas isso não é uma competição! Vocês entenderam o que fizeram? Conseguem explicar?

Daiane: - A resposta é 4,083? Mas o três é uma dízima infinita!

Professor: - A questão não é: Qual a resposta correta? E, sim, por que essa resposta é correta? Como se chegou a essa resposta?

Francisco: - Mas nos diga, é ou não é?

Professor: - Como vocês chegaram a essa resposta?

Roberto: - Depois de montar a tabela, como o G2 fez, a gente montou a igualdade $\frac{13}{x}=\frac{12}{7} \frac{156}{84}$, e depois multiplicou cruzado. E então?

Professor: - Porque essa multiplicação? Qual o motivo para se manter essa razão e não sua inversa?

Francisco:- Xiiiiiii!, Acho que está errado! Espere aí! E se nós compararmos as grandezas ou variáveis?

Outros estudantes do grupo: - Explique isso! O que você está pensando? (Material do professor, 16/03/2014).

E voltaram-se à discussão.

Após algum tempo, Israel do G2 disse: “- Não sei escrever, nem aplicar fórmulas, mas deixa eu te explicar o que eu pensei”. (Material do professor, 16/03/2014). Este estudante receberá destaque neste momento. Ele é mecânico de 47 anos, está há mais de 30 anos longe da escola, tem dificuldade para escrever e se expressar "no papel"- como disse. Todavia, construiu o seguinte raciocínio que motivou o professor e possibilitou um melhor entendimento do problema pelos grupos, quando o professor transcreveu o que ele dizia.

Agora na história não tem somente dias e caldeiras. Tem funcionários também. Então, pense que o número de caldeiras seja qualquer um, mas um número que não mude. Se diminuir o número de funcionários vai ser preciso mais dias pra produzir esse número de 'caldeira'. Ou seja, o número de dias vai ser diferente, tem que ser invertido na hora da conta. Por isso, devemos colocar nessa ordem: $\frac{13}{x}=\frac{12}{7}=\frac{156}{84}$. (Material do professor, 16/03/2014).

Nesse momento, o professor percebeu quão importante é valorizar os pensamentos produzidos pelos estudantes, a partir de suas experiências e suas influências no processo da resolução de problemas. $\mathrm{O}$ construto desse estudante estava muito próximo do formal e o docente lhe pediu que continuasse a pensar no problema de modo a conseguir entender o que precisava ser feito e utilizado para se alcançar melhor compreensão sobre os conceitos nele 
envolvidos e formalizar os princípios necessários para resolver problemas sobre regra de três, tanto simples quanto composta.

$\mathrm{Na}$ aula seguinte foram retomadas as atividades. Muito ainda restava para se ajustar, mas o professor considerou a metodologia promissora e, como haveria outros problemas, acreditava que estariam aperfeiçoando-se com a prática.

Alguns estudantes dos grupos tentaram abandonar a atividade e permaneceram dispersos $^{16}$, dizendo ao professor que não sabiam, que detestavam Matemática, que nunca se deram bem com 'a matemática' e que não tinham vontade de estudá-la, postura essa que divergia de suas posições participativas do dia anterior. O professor tentou convencê-los da importância de participar das aulas e de aprenderem Matemática, pois isso seria de vital importância para seus trabalhos.

\subsection{Percalço no trabalho através da Resolução de Problemas - a desmotivação}

Nesse momento fez-se necessário refletir sobre a atuação docente face a esse acontecimento. Essa situação retrata alguns dos conflitos que atravessam as salas de aula de Matemática e que não devem passar despercebidos ou ignorados, pois quando buscamos um ensino-aprendizagem baseado na proposta da Resolução de Problemas, devemos conceber cada estudante como um componente do processo de interação nos âmbitos social, histórico e cultural. Deixá-los à margem da sala de aula seria negar-lhes a participação na constituição/construção de suas aprendizagens/de seus conhecimentos.

Cada estudante é um ser singular e carece de atenção e motivação para poder produzir uma visão tão diferentemente benéfica e producente nas aulas de Matemática, quanto propõe a Resolução de Problemas, fornecendo-lhes a possibilidade de se moverem juntos com o grupo e/ou professor, para um objetivo comum. Entendemos que não devemos forçar os estudantes ao estudo quando os mesmos não desejam atuar nesse cenário, mas que devemos, enquanto mediadores do processo de ensino-aprendizagem, indicar e conscientizá-los da importância dessa participação e desse movimento, em sua formação, enquanto sujeitos sociais, no momento histórico que estão vivendo.

Mora (2012) e Prediger, Berwanger e Mors (2009) abordaram questões pertinentes ao desinteresse de estudantes que nos levaram a analisar o estudo. Dessarte, conhecer e auxiliar cada estudante, com suas deficiências, dificuldades e carências, é parte essencial do papel do

\footnotetext{
${ }^{16}$ Para uma leitura mais detalhada sobre desmotivação e desinteresse dos estudantes recomendamos a leitura de Zenti (2000), Pozo (2002), Knuppe (2006), Mora (2012).
} 
professor na sala de aula. Esses elementos podem se tornar impedimentos/obstáculos para que os estudantes possam ser coautores na construção de novos conhecimentos, colaborando e cooperando no trabalho do ensino-aprendizagem de Matemática através da Resolução de Problemas. Trata-se de um trabalho árduo e, muitas vezes, demanda tempo e diálogo entre professor-estudante.

Conforme Pozzo (2002), "normalmente, não é que eles não estejam motivados, que não se movam em absoluto. Mas, sim, que se movam para coisas diferentes e em direções diferentes daquelas pretendidas por seus professores" (p. 139). Nesse sentido, acreditamos que não cabe ao docente lutar contra esse gradiente, mas sim propor atividades que sejam, aos seus olhos, tão refratárias quanto aquelas que os afastam, não dos objetivos do professor, mas de sua participação ativa na construção de seu conhecimento.

Voltando ao caso proposto, o professor conversou com os estudantes retraídos e desmotivados de cada grupo. A conversa se iniciou pelo problema proposto e o discurso não foi direto a esses alunos. Perguntou-lhes o que acharam do problema e se reconheciam algumas situações que poderiam ter significado em seus trabalhos, enquanto futuros traçadores de caldeiraria. Expôs, aos estudantes, situações do cotidiano desses profissionais, onde a Matemática e o desenho geométrico são conhecimentos essenciais à sua atuação. Pediu-lhes que participassem mais do problema, não apenas como um exercício ofertado para nota, mas como uma atividade onde seus pensamentos e conhecimentos seriam importantes na construção daquela resolução. Orientou cada componente a questionar o colega de grupo sobre o que significava aquela construção. Informou-lhes que a postura passiva diante do problema não lhes permitiria lograr êxito frente aquela proposta de prática na Resolução de Problemas.

Por haver pessoas mais maduras e determinadas nos grupos, eles os acolheram tentando motivá-los e explicando-lhes o progresso que haviam atingido, até o momento, na resolução do problema dado. Não tivemos óbices com a comunicação entre os componentes dos grupos. Eles conversaram entre si, trocaram ideias e lançaram mão do pensar-em-alta-voz para explicar aos demais suas ideias e pensamentos acerca dos conceitos produzidos e suas resoluções, mostrando assim suas próprias maneiras de aprender.

Esse fato propiciou reflexão sobre suas ações e ações sobre suas reflexões, o que os fez pensar sobre seus feitos, acertos, erros, desvios. Também consideraram as possibilidades de conseguir produzir e ampliar suas capacidades de pensar, refletir e agir de forma coletiva diante dos problemas, atingindo, assim, um dos objetivos da aula, fazendo uso da Resolução de Problemas. 
Ao comparar o desempenho dos grupos com relação ao primeiro dia, percebemos o progresso obtido tanto em termos de participação ativa, quanto na expressão do raciocínio dos estudantes pela Resolução de Problemas, o que confirmou a proposição de Zuffi e Onuchic (2007):

[...] a prática da Resolução de Problemas, como uma tarefa intelectual exigente, facilita o acionamento da metacognição, dos processos de autorregulação das ações cognitivas e caracteriza-se como importante forma para o desenvolvimento dos processos mentais superiores. (Ibidem, p. 92)

No momento da entrega dos trabalhos, antes do registro das resoluções na lousa e da plenária, o G1 produziu um texto como quem está iniciando um trabalho de formalização de conceitos, com pouca escrita e com símbolos matemáticos suficientes para demonstrar o que fora produzido de forma clara e sucinta. Por sua vez, o trabalho entregue pelo G2 foi feito na forma de narrativa, comentando o passo-a-passo do grupo para buscar a solução do problema.

\section{3 Últimos passos do problema}

Agora falaremos da explanação das resoluções, onde algum representante do grupo foi até a lousa expor o que haviam conseguido fazer. Consideramos esse momento muito importante para a aprendizagem, no qual os estudantes apresentaram suas resoluções para discussão e para fomentar a formalização dos conceitos matemáticos almejados para o problema.

Ao exporem suas ideias na lousa ou à frente da classe, cada representante dos grupos buscou uma discussão geral sobre o que haviam feito e acharam da atividade. Podemos dizer que dez dos doze estudantes gostaram da proposta e se sentiram motivados a resolver os problemas, percebendo-se estimulados a pensar em coisas novas a partir do que já conheciam e que a Matemática pode ser criada de maneira agradável quando se decide participar ativamente.

Quanto aos outros dois, um disse que não havia entendido ainda sua participação no processo com base em sua dificuldade com Matemática e que precisaria de mais ajuda. O último estudante disse que não gostou porque simplesmente não se identificava com a Matemática e com nada que estivesse a ela relacionado, colocando-se assim numa postura de oposição. Sobre esse estudante, nada podemos dizer sobre seu progresso, pois foi um dos estudantes que se evadiu do curso a partir da terceira aula. Aquele outro, Ignácio do G1, que não havia entendido sua participação e, até certo ponto, pretendia ficar à margem da sala de aula, conseguiu concluir o curso e foi um dos estudantes que mais se desenvolveu 
matematicamente. Nas considerações finais, colocaremos sua fala sobre a aprendizagem que obteve no curso, bem como a dos outros quatro colegas que conseguiram concluí-lo.

Na Resolução de Problemas, o foco não está na resposta ou na solução do problema, mas sim nos pensamentos produzidos e engendrados pelos conceitos e princípios que possam destacar a resolução do problema que se pretende estudar e avançar nos meios, e não simplesmente nos fins. Não vamos apresentar aqui os cálculos que resolveriam o problema matemático, mas consideraremos o construto dos estudantes sobre os procedimentos de suas resoluções.

Daiane do G1 e Helena do G2 foram as representantes escolhidas pelos respectivos grupos para apresentarem seus resultados. Daiane foi à lousa e simplesmente começou a escrever de forma sistêmica a resolução que obtiveram. Mantiveram a resposta 4,083... e estavam convencidos da mesma. Contudo, desviaram-se quando não analisaram a proporcionalidade dos dados, baseados num procedimento multiplicativo, a que chamaram de multiplicação em "X”, ou seja, multiplicação cruzada.

Por sua vez, Helena iniciou dizendo: “- A nossa solução é diferente da deles. Espero que esteja correta!” (Material do professor, 23/03/2014). Seguiu-se uma discussão que deu continuidade à fala de Israel, já mencionada, e que, de maneira nada sistêmica, sem uma linguagem matemática formal, porém com bastante clareza de raciocínio, possibilitava atividades de autorregulação para demonstrar a resposta que haviam obtido, 12 dias, e que resolveu o problema, através de uma análise incipiente sobre proporção.

A partir desse momento, o professor tinha como objeto de trabalho duas soluções distintas, obtidas de maneiras diferentes, que lhes forneciam um cenário muito bom para a plenária, uma vez que as escritas eram de naturezas complementares, no sentido de uma ser formalmente matemática e a outra descritivamente explicativa. De certa forma, as resoluções dos grupos diferiram a partir da análise da proporcionalidade entre as variáveis. Fato esse que chamou a atenção do professor para que, na hora da formalização, pudesse abordar tais conceitos, sendo que a motivação para isso já estava latente.

Daí, então, o professor conseguiu boas discussões na plenária, eximindo as dúvidas decorrentes e, por fim, a formalização dos resultados. Nesse momento, todos os estudantes estavam muito atentos para saber o que lhes faltava para apresentarem a resposta correta. E antes de resolver o problema propriamente dito, o professor buscou expor os conceitos de proporção. À medida que explicava, percebeu que alguns estudantes já haviam conseguido entender onde, de fato, haviam errado ou em que passo haviam se desviado. Prontamente, corrigiam suas respostas. Foi quando alguém disse: "- Ah! Era isso? Agora entendi!" e, 
claramente, apontavam em suas análises as situações onde as grandezas eram direta ou inversamente proporcionais.

Atentamos para o fato de se analisar as situações por um prisma diferente na produção de conceitos, pois primava-se inicialmente pela regra de três composta. O conceito de proporcionalidade que, em princípio, deveria ser definido a priori, veio a se consolidar em decorrência do problema proposto, diferentemente dos conceitos de números racionais, suas operações e regras de três simples que foram utilizados como ferramentas necessárias à resolução do problema.

Foi uma atividade que consideramos sui generis, que ampliou a concepção dos sujeitos daquele ambiente escolar e suas percepções de ensino-aprendizagem, pois a Resolução de Problemas promoveu interação entre os estudantes e a coautoria pela própria aprendizagem tomou forma.

\section{Considerações finais}

A Resolução de Problemas, no caso proposto, nos permitiu refletir sobre nossas ações e práticas no âmbito educacional. Ações e práticas essas que promovem outras ações e reforçam as práticas como propósitos que tonificam atividades através da Resolução de Problemas. Falamos de problemas que tenham, em sua composição, a construção de conceitos e a produção de discursos voltados a vivência dos sujeitos como modo de compreensão do mundo histórico e social. É certo que a Resolução de Problemas altera as percepções que temos de Matemática, pois nos permite refletir sobre ela, implicando, assim, em novas ações e resoluções que engendram práticas, e essas agenciam as atividades humanas.

Com relação ao curso de Matemática do PRONATEC, onde essa pesquisa atuou, podemos dizer que, do primeiro ao último problema proposto pelo professor seguindo a Resolução de Problemas, percebemos um avanço significativo no desenvolvimento dos estudantes e suas aprendizagens. Isso foi refletido nas avaliações e nos depoimentos dos estudantes que permaneceram até o final e que elencaremos a seguir. Infelizmente, ainda é característica dos cursos do PRONATEC, no cenário nacional, um alto índice de evasão ${ }^{17}$ que, no nosso caso, foi de $41,67 \%$ e os motivos são variados.

Acreditamos que não se deve propor problemas aos estudantes que primem simplesmente por um aumento gradativo de dificuldade ou nível, mas propor problemas que

\footnotetext{
${ }^{17}$ Para melhor conhecer estes dados sobre evasão nos cursos do PRONATEC, acessar: <http://www.bbc.co.uk/portuguese/noticias/2014/09/140901_evasao_pronatec_eleicoes_salasocial_ru>
} 
estejam além do NDR e que, através da mediação do professor, possam ser resolvidos na potência de seus NDP's, estando assim o problema situado na ZDP dos estudantes, onde a Resolução de Problemas opera transversalmente pelas suas aprendizagens.

A Resolução de Problemas, da maneira como hoje é trabalhada pelo GTERP, tem o caráter de prática, e não apenas de propostas de atividades. Mas práticas que podem ser percebidas em diferentes atividades, que têm o delineamento social, histórico e cultural e que podem ser concebidas através de atividades matemáticas, como foi feito neste trabalho.

A citação de Antônio Miguel, na fundamentação teórico-metodológica por sua concepção de atividade humana, mostra-se assim:

[...] uma prática não caracteriza univocamente uma atividade, uma vez que uma mesma prática pode ser realizada em diferentes atividades, assumindo significações diversas em função dos diferentes propósitos que a constituem nessas diferentes atividades. Assim, por exemplo, práticas de orientação espacial podem ser realizadas na atividade náutica, na atividade agrícola, na atividade topográfica, na atividade astronômica, mobilizando propósitos, instrumentos, métodos e significações diferentes. (MIGUEL, 2010, p. 48).

Fazendo o deslocamento conceitual dessa definição para a teorização da Resolução de Problemas como uma prática sociointeracionista, no bojo de seu campo de estudo filosófico, entendemos que ela pode ser realizada através de atividades educacionais, nos âmbitos da formação de professores, ensino, aprendizagem, avaliação, história da Educação Matemática, filosofia da Educação Matemática, psicologia da Educação Matemática, trabalho cooperativo e colaborativo e etc., o que vem confirmar as dimensões desse campo, como propomos no início do artigo, sendo elas: metodológica, epistemológica, cognitiva, ontológica, política, educacional, social, histórica e cultural.

Como levantamos acima, somente cinco estudantes conseguiram concluir o curso, e seguem seus relatos sobre a formação matemática construída através da Resolução de Problemas:

Ignácio [G1]: - Gostei desse jeito do senhor dar aula. A Resolução de Problemas foi muito boa pra mim, porque consegui entender onde posso usar a matemática e que, mais ainda, consigo pensar quando recebo um problema pela frente. Essa matemática é mesmo importante.

Roberto [G1]: - Gostava da matemática, mesmo sem entender muito bem. Nunca tive aulas de matemática do jeito que você trabalha. É bem diferente! Eu gostei. Já cheguei algumas vezes aqui cansado, sem vontade de aprender. Mas quando vi o problema que 'iamos' trabalhar me motivei.

Daiane [G1]: - Eu sempre gostei de matemática. Mas, não que sempre entendesse 'ela'. Trabalho de camareira o dia todo, não tenho nem tempo pra estudar fora daqui, e a matemática com a resolução de 'problema' me deixava feliz porque eu fazia meus estudos aqui mesmo, e conseguia aprender. Já cheguei até aprender antes de você ensinar!

Heloiza [G2]: - Reconheço a importância da matemática na minha vida. Fiquei preocupada de conseguir aprender fórmulas, 'que' eu sou péssima nisso! Mas, você acredita que num dos problemas eu cheguei a encontrar a fórmula da área do triângulo sozinha? Adorei estudar 
matemática pela resolução de problemas. Isso vai me ajudar, porque agora vou estudar pro vestibular também.

Israel [G2]: - Eu já te contei que não me dou muito com o 'escreve das coisas', eu consigo pensar bem na matemática. Trabalho numa oficina, que é 'minha mesmo'. Ganho o suficiente pra viver eu, mais a patroa e meus 4 filhos. Na hora que me disseram que eu 'ia' ter aula de matemática fiquei feliz; mas, quando você falou que iria ter que explicar o meu pensamento, quase desanimei. Hoje, eu vejo que isso foi bom, por que eu acho que já consigo me expressar melhor e até ajudo meu filho na tarefa de matemática em casa, porque entendo o que ele fala e quer fazer. (Material do professor, 30/06/2014).

São esses os discursos que foram gravados no último dia de aula, onde o professor buscou perceber os efeitos da prática da Resolução de Problemas em suas aulas, na visão dos cinco estudantes que chegaram ao final do curso. Discursos esses que, além da gratidão e do reconhecimento dos estudantes, demonstram que a Resolução de Problemas é mais que uma metodologia, é um campo de estudo filosófico, que possui em sua composição a prática sociointeracionista e a teoria/teorização a ela relacionada.

\begin{abstract}
Entendemos que Filosofia da Educação Matemática se caracteriza como um refletir filosófico sobre Educação Matemática em seus aspectos teóricos e práticos, que se nos apresentam de forma inseparável, pois ao mesmo tempo em que uma teoria pode indicar ou explicitar uma prática, a uma prática subjaz uma teoria que a indica ou a explicita. (KLUTH; ANASTACIO, 2009 apud ONUCHIC; ALLEVATO, 2011, p. 86).
\end{abstract}

A Resolução de Problemas como propomos, percebemos e a trabalhamos não se identifica apenas como metodologia. As referências bibliográficas sobre Resolução de Problemas e congressos que discutem e abordam o tema, desde seus referenciais teóricos às análises empíricas, indicam uma produção bastante forte para caracterização da mesma como uma teorização, o que é tema de estudos do GTERP atualmente.

\title{
Referências
}

BICUDO, M. A. V. Filosofia da Educação Matemática segundo uma Perspectiva Fenomenológica. São Paulo: Editora UNESP,2010.

BRASIL. Secretaria de Educação Profissional e Tecnológica. IFSP - Campus Sertãozinho -. Projeto Pedagógico do Curso de Traçador de Caldeiraria do PRONATEC. Pró-reitora de extensão, Instituto Federal de Educação, Ciência e Tecnologia de São Paulo. Sertãozinho. 2013.

CASSIANO, P. M. D.; ANDRARE, A. S. Recognição e Criatividade, como Cognição Inventiva, nos Processos de Interação em uma Sala de Aula do Ensino Fundamental. 2010. 290 p.

Dissertação (Mestrado em Psicologia)- Faculdade de Filosofia, Ciências e Letras de Ribeirão Preto, Universidade de São Paulo. São Paulo, 2010.

DAMÁSIO, A. O Mistério da Consciência: do corpo e das emoções do conhecimento de si. São Paulo: Companhia das Letras, 2000.

DUARTE, N. A Escola de Vigotski e a Educação Escolar: algumas hipóteses para uma leitura pedagógica da psicologia histórico-cultural. Psicologia USP, São Paulo, v. 7, n. 1/ 2, p. 17-50.1996. 
FLAVELL, J. H.; MILLER, P. H.; MILLER, S. A. Desenvolvimento cognitivo. 3. ed. Porto Alegre: Artes Médicas, 1999.

FLORES-MENDOZA, C.; COLOM, R. Introdução à Psicologia das Diferenças Individuais. Artmed: Porto Alegre, 2008.

FREIRE, P. Pedagogia da autonomia: saberes necessários à prática educativa. São Paulo: Paz e Terra, 1996.

FRISON, L. M. B. Autorregulação da Aprendizagem: atuação do pedagogo em espaços nãoescolares. 2006. 342 f. Tese (Doutorado em Educação) - Faculdade de Educação, Pontifícia Universidade Católica do Rio Grande do Sul, Porto Alegre, 2006.

GONZÁLEZ, F. E. Metacognición y tarefas intelectualmente exigentes: el caso de la resolución de problemas matemáticos. Zetetiké, Campinas, v. 6, n. 9, p. 59-87, Jul/ Dez, 1998.

KNUPPE, L. Motivação e desmotivação: desafios para as professoras. Educar, Curitiba, n. 27, p. 277290, 2006.

MACIEL, C. I. S.; LEAL JR, L. C.; RIBEIRO, A. Partindo do Surgimento de Indústrias-de-Fundo-deQuintal, Sertãozinho se Tornou uma das Melhores Cidades Para se Viver no País. Revista Iluminart, Sertãozinho, n. 7, p. 110-115. 2011.

MIGUEL, A. Percursos Indisciplinares na Atividade de Pesquisa em História (da Educação Matemática): entre jogos discursivos como práticas e práticas como jogos discursivos. Bolema, Rio Claro, v. 23, n. 35, p. 1-57, 2010.

MORA, E. Psicopedagogia infanto-adolescente Puberdade e adolescência. Nova Floresta: Cultura S.A, 2012.

ONUCHIC, L. R. Ensino-aprendizagem de Matemática através da resolução de problemas. In: BICUDO, M. A. V. (Org.). Pesquisa em Educação Matemática. São Paulo: Editora UNESP, 1999. p.199-220.

ONUCHIC, L. R.; ALLEVATO, N. S. G. Novas reflexões sobre o ensino-aprendizagem de matemática através da resolução de problemas. In: BICUDO, M. A. V.; BORBA, M. C. (Org.) Educação Matemática: pesquisa em movimento. São Paulo: Cortez, 2004. p. 212- 231.

ONUCHIC, L. R.; ALLEVATO, N. S. G. Pesquisa Em Resolução de Problemas: Caminhos, Avanços e Novas Perspectivas. Bolema, Rio Claro, v. 25, n. 41, p. 73-98. 2011.

ONUCHIC, L. R.; ALLEVATO, N. S. G.; NOGUTI, F. C. H.; JUSTULIN, A. M. (Orgs.). Resolução de Problemas: Teoria e Prática. Paco Editorial. Jundiaí. 2014.

POLYA, G. A arte de resolver problemas. Rio de Janeiro: Interciência, 1978.

POZO, J. I. Aprendizes e mestres: a nova cultura da aprendizagem. Porto Alegre: Artmed, 2002.

PREDIGER, J.; BERWANGER, L.; MORS, M. F. Relação Entre estudante e Matemática: Reflexões Sobre o Desinteresse dos estudantes Pela Aprendizagem Desta Disciplina. Revista Destaques Acadêmicos, Lajeado, n. 4, p. 23-32, 2009.

REGO, T. C. Memórias de Escola: cultura escolar e constituição de singularidades. Petrópolis, RJ: Vozes, 2003. 
REIS, E., LÖBER, M. L., BOLZAN, L. M. Discussão e Aplicação do Método do Protocolo Think Aloud em Pesquisas sobre Processo Decisório. In.: IV ENCONTRO DE ADMINISTRAÇÃO DA INFORMAÇÃO. 2013, Bento Gonçalves/ RS. 16 f. Anais...Bento Gonçalves, EnADI 2013, 2013.

ROCHA, T. G.; PINHEIRO, F. P. H. A. Políticas Cognitivas da Psicologia Comunitária: a meio caminho entre a recognição e a invenção. Psicologia \& Sociedade, Belo Horizonte, v.23, n.3, p. 486495, 2011.

VIGOTSK, L. S. A construção do pensamento e da linguagem. Trad. Paulo Bezerra, São Paulo: Martins Fontes, 2001.

VYGOTSKI, L. S. Obras escogidas. Volume I. Madrid: Centro de Publicaciones del M.E.C. y Visor Distribuciones, 1991.

VYGOTSKI, L. S. Obras escogidas. Volume II. Madrid: Centro de Publicaciones del M.E.C. y Visor Distribuciones, 1993.

VYGOTSKY, L. S. Imaginação e Criação na Infância. 1 ed. Trad.Zoia Prestes. Sâo Paulo: Ática, 2009.

VYGOTSKY, L. S. A formação social da mente. São Paulo: Martins Fontes, 1984.

VYGOTSKY, L. S. Pensamento e linguagem. São Paulo: Martins Fontes, 2008.

ZENTI, L. Aulas que seus estudantes vão lembrar por muito tempo: motivação é a chave para ensinar a importância do estudo na vida de cada um de nós. Nova Escola, São Paulo, v. 134, p. 65-68, abril, 2000 .

ZUFFI, E. M.; ONUCHIC, L. R. O Ensino-Aprendizagem de Matemática Através da Resolução de Problemas e os Processos Cognitivos Superiores. Unión-Revista Iberoamericana de educação Matemática, Barcelona, n. 11, p. 79-97, setembro, 2007.

Submetido em Abril de 2015. Aprovado em Agosto de 2015.

\section{Errata:}

No artigo "Ensino e Aprendizagem de Matemática Através da Resolução de Problemas Como Prática Sociointeracionista” publicado no periódico Bolema 29 (53): 955 - 978, na página 977 onde se lia:

"MACIEL, C. I. S.; LEAL J. R. L. C.; RIBEIRO, A. Partindo do Surgimento de Indústriasde-Fundo-de-Quintal, Sertãozinho se Tornou uma das Melhores Cidades Para se Viver no País. Revista Iluminart, Sertãozinho, n. 7, p. 110-115. 2011.”

Leia-se

"MACIEL, C. I. S.; LEAL JR, L. C.; RIBEIRO, A.. Partindo do Surgimento de Indústrias-deFundo-de-Quintal, Sertãozinho se Tornou uma das Melhores Cidades Para se Viver no País. Revista Iluminart, Sertãozinho, n. 7, p. 110-115. 2011.” 